\title{
Exo-ethylene application mitigates waterlogging stress in soybean (Glycine max L.)
}

\author{
Yoonha Kim ${ }^{1+} \mathbb{D}$, Chang-Woo Seo ${ }^{1 \dagger}$, Abdul Latif Khan², Bong-Gyu Mun', Raheem Shahzad ${ }^{1}$, Jeung-Woo Ko ${ }^{1}$, \\ Byung-Wook Yun', Soon-Ki Park ${ }^{1 *}$ and In-Jung Lee ${ }^{1 *}$
}

\begin{abstract}
Background: Waterlogging (WL) is a key factor hindering soybean crop productivity worldwide. Plants utilize various hormones to avoid various stress conditions, including WL stress; however, the physiological mechanisms are still not fully understood.

Results: To identify physiological mechanisms during WL stress, different phytohormones, such as ethephon (ETP; donor source of ethylene), abscisic acid, gibberellins, indole-3-acetic acid, kinetin, jasmonic acid, and salicylic acid were exogenously applied to soybean plants. Through this experiment, we confirmed the beneficial effects of ETP treatment. Thus, we selected ETP as a candidate hormone to mitigate WL. Further mechanistic investigation of the role of ETP in waterlogging tolerance was carried out. Results showed that ETP application mitigated WL stress, significantly improved the photosynthesis pigment, and increased the contents of endogenous $\mathrm{GA}_{s}$ compared to those in untreated plants. The amino acid contents during WL stress were significantly activated by EPT treatments. The amino acid contents were significantly higher in the $100 \mu \mathrm{M}$ ETP-treated soybean plants than in the control. ETP application induced adventitious root initiation, increased root surface area, and significantly increased the expressions of glutathione transferases and relative glutathione activity compared to those of non-ETP-treated plants. ETP-treated soybeans produced a higher up-regulation of protein content and glutathione S-transferase (GSTs) than did soybeans under the WL only treatment.
\end{abstract}

Conclusions: In conclusion, the current results suggest that ETP application enabled various biochemical and transcriptional modulations. In particular, ETP application could stimulate the higher expression of GST3 and GST8. Thus, increased GST3 and GST8 induced 1) increased GSH activity, 2) decreased reactive oxygen species (ROS), 3) mitigation of cell damage in photosynthetic apparatus, and 4) improved phenotype consecutively.

Keywords: Antioxidant, Gibberellin, Photosynthesis efficiency, Plant growth regulator, Reactive nitrogen species, Reactive oxygen species

\section{Background}

The world's climate has been rapidly changing due to increased carbon dioxide concentration in the atmosphere [1]. Such changes in global climate have severely influenced agricultural land and increased detrimental abiotic stresses such as drought, salinity, thermal, ultra violet, ozone, and flooding stresses. These environmental

\footnotetext{
* Correspondence: psk@knu.ac.kr; ijlee@knu.ac.kr

${ }^{\dagger}$ Yoonha Kim and Chang-Woo Seo contributed equally to this work.

'Division of Plant Biosciences, Kyungpook National University, Daegu

702-701, South Korea

Full list of author information is available at the end of the article
}

stresses hinder crop productivity [2-6]. Some of the underlying stress mechanisms are still not fully understood for all crops. Understanding stress tolerance and mitigation responses, and how to further improve these are important to ensure sustainable agriculture production for the ever-increasing human population [4-7]. Among abiotic stresses, flooding is caused by increased water levels in the cultivation field [8]. Flooding negatively influences the physiological functions of plants, which leads to reduced photosynthesis, imbalance in phytohormones, reduced nutrients uptake, premature

(c) The Author(s). 2018 Open Access This article is distributed under the terms of the Creative Commons Attribution 4.0 International License (http://creativecommons.org/licenses/by/4.0/), which permits unrestricted use, distribution, and 
fruit drop, stunted growth, and reduced yield $[9,10]$. For acclimation to hypoxia, plants morphologically change their intercellular formation by developing aerenchyma cells in plant roots, which trigger several signal regulators such as nitric oxide, reactive oxygen species (ROS), and plant hormones especially ethylene (ET) [11]. Endogenous ET has been associated with the formation of aerenchyma cells however, this depends on the level, intensity, and duration of the flooding stress [12]. Both types of primary aerenchyma, e.g., schizogenous and lysigenous formations, are promoted in subaquatic rice plants, maize, barley, and wheat roots under waterlogged conditions. In contrast, in dryland crop plants such as soybean, the secondary type of aerenchyma is found and differentiated from the secondary meristem, and is observed in the stem, taproot, hypocotyl, adventitious roots, and root nodules [13-16]. In addition, this further signals a plethora of physiological networks associated with plant growth and flooding stress. It involves activating endogenous phytohormones (e.g., abscisic acid: $\mathrm{ABA}$, gibberellins: GA, and auxin), and antioxidant enzymes (e.g., glutathione, peroxidase, and catalases) [15, 17, 18]. Alternatives such as exogenous plant growth regulators (PGRs) have recently been suggested to ameliorate the negative effects of flooding stress in plants. According to NASA, approximately 17 million $\mathrm{km}^{2}$ of the worldwide land area has been exposed to flooding [7, 19, 20]. However, among flooding conditions, waterlogging (WL) is a more common problem than submergence. WL stress in field conditions occurs for several reasons including overflow of rivers and heavy rainfall [9].

The physiological response of different crops to WL is variable. Soybean is one of the most important crops due to its high nutritional value [9]. In South Korea, soybean is not only regarded as an important field crop due to its high nutritional value, but it is also regarded as a higher income crop than paddy field crops such as rice [21]. According to a study by Nguyen et al. [5], soybean yield was $17 \%$ (vegetative stage) and 50\% (reproductive stage) lower when exposed to WL stress conditions than when exposed to non-stress conditions. Soybean yield is also estimated to have decreased by $25 \%$ due to flooding stress in Asia, North America, and other regions of the world where soybean is rotated with rice in paddy fields [22]. Oosterhuis et al. [23] and Mustafa and Komatsu [22] reported reductions in soybean yield of $17-43 \%$ during the vegetative stage and $50-56 \%$ during the reproductive stage, respectively, due to flooding stress. Thus, several soybean breeders have been developed as tolerant varieties against WL stress and the identification of tolerance mechanisms under WL conditions has been studied [5, 9, $24,25]$. Our research team recently reported the physiological differences between a WL-tolerant soybean variety and a WL susceptible soybean variety and confirmed significant alteration in the different endogenous hormone levels (ABA, ET, GA, salicylic acid: SA, and jasmonic acid: JA) in contrasting soybean lines as well as the differences in antioxidant activities and root architecture such as lateral roots and aerenchyma cells [9]. Among several physiological responses, flooding responds to different ET levels. ET is biosynthesized by a short haul pathway in comparison to other plant hormones and is produced by 1-aminocyclopropane-1-carboxylic acid oxidation; therefore, oxygen is the main component for the production of ET $[26,27]$. Plants may not produce enough ET without a supply of oxygen. However, ET production is significantly increased under WL conditions due to increased 1-aminocyclopropane-1-carboxylic acid synthase [26]. Furthermore, ET has been known to mitigate WL stress via the development of aerenchyma cells with crosstalk in oscillation with ABA, GA, indole-acetic-acid (IAA), and kinetin (KT) $[15,28,29]$. Conversely, ET can interact with JA and SA to induce the development of adventitious roots and aerenchyma cells in soybean [30, 31]. Therefore, the present study aimed to confirm the effect of exogenously applied PGRs (including ET) during WL stress by evaluating phenotypic characteristics. We then carried out a further experiment to identify the influence of morphological, physiological, and genetic responses of soybean plants through the exogenous application of selected PGRs among various plant hormones.

\section{Methods}

\section{Selection of proper plant hormone}

In the present study, we performed two experiments. Experiment I (EP I) was conducted to screen the appropriate PGRs to soybean plants to enhance resistance against WL stress conditions. Thus, we applied different types of PGRs such as ABA, ET (ethephon; ETP), GA 4 , IAA, KT, JA, and SA to soybean plants grown under WL stress conditions. Experiment II (EP II) was carried out to identify the physiological and biochemical mechanisms of phytohormone application during WL stress mitigation.

\section{Plant growth condition and application of PGRs (EP I)}

We used the Daewon soybean variety (Glycine max L.) as the plant material because it is the most common variety of soybean and is broadly grown in South Korea. The seeds were donated by the National Institute of Crop Science, Rural Development Administration, South Korea. The seed surface was sterilized with $70 \%$ ethanol and then thoroughly rinsed with autoclaved double distilled water. Seeds were sown in plastic trays (50 holes, $40 \mathrm{~cm} \times 20 \mathrm{~cm}$ ), filled with autoclaved horticultural soil (Tobirang; Baekkwang Fertility, South Korea), and grown in a greenhouse located at the Kyungpook National University, Daegu, South Korea. Uniformly grown seedlings were transferred to plastic pots (six holes, $455 \mathrm{~mm} \times$ 
$340 \mathrm{~mm} \times 180 \mathrm{~mm}) 10$ days after germination. When the soybean plant reached the V2 growth stage, we applied WL stress for 2 weeks (14 days). PGRs were applied to soybean seedlings $1 \mathrm{~h}$ after the WL treatment. Detailed information about PGRs applied is provided in Additional file 1: Table S1.

\section{Evaluation of resistance to WL stress (EP I)}

To evaluate the mitigation effects on WL stress, we measured growth attributes, such as plant height, chlorophyll content, and chlorophyll fluorescence, during and after WL treatment. The chlorophyll content was measured with a chlorophyll content meter (CCM-300; Opti-Sciences, USA) and chlorophyll fluorescence data were recorded with a chlorophyll fluorimeter (OS5p+; Opti-Sciences, USA). The selection of the proper plant hormones to enhance the resistance of soybean to WL stress was conducted three times under greenhouse conditions and each experimental set consisted of three replications.

\section{Plant growth condition and PGRs application (EP II)}

We confirmed the stress resistance effect during EP I. ETP application resulted in higher resistance to WL stress in the soybean than in the other PGRs treatments. Thus, we selected ETP and applied three different concentrations of ETP to soybean plants to identify the physiological and biochemical mechanisms against WL stress.

\section{Plant growth condition and ETP application (EP II)}

We used the same seeds, soil, and pots in EP II as in EP I for seed germination; however, the seeds were grown in a growth chamber (Day $30{ }^{\circ} \mathrm{C}[14 \mathrm{~h}] /$ Night $22{ }^{\circ} \mathrm{C}[10 \mathrm{~h}]$, relative humidity $70 \%$, light intensity $1000 \mu \mathrm{mol} \mathrm{m}^{-2} \mathrm{~s}^{-1}$ ) to collect accurate data. After the germination of seeds, uniformly growing soybean seedlings were selected and transplanted into the six-hole pots (the same size as in EP I) and maintained in the growth chamber. WL stress was applied to soybean plants during the V2 stage (fully developed trifoliate leaf at node immediately above the unifoliate node) and the water level was maintained at $10-15 \mathrm{~cm}$ above the soil surface for 10 days. Three different concentrations of ETP $(50 \mu \mathrm{M}, 100 \mu \mathrm{M}$, and $200 \mu \mathrm{M})$ were sprayed on the soybean shoot areas $1 \mathrm{~h}$ after subjection to WL (Additional file 1: Table S1).

\section{Analysis of chlorophyll content and chlorophyll fluorescence (EP II)}

Chlorophyll content and fluorescence data were measured at 5, 10, and 15 days after WL. The chlorophyll content and fluorescence data were measured using the same methods as those mentioned for EP I. Data were collected three times and each replication was composed of seven plants $(n=7)$.

\section{Endogenous hormones analysis (EP II)}

To analyze endogenous GA contents, we harvested shoot samples at 5, 10, and 15 days after the WL treatment, and harvested shoot samples grown under non-stress conditions at the same time periods. Plant samples were immediately placed in liquid nitrogen followed by freeze-drying (ISE Bondiro Freeze Dryer; Operon, South Korea) for 5 days. Thoroughly dried plant samples were ground into a fine powder, which was used for GA analysis. A $0.3 \mathrm{~g}$ dried sample was used for GA analysis and followed the same analysis protocol as that described by Kim et al. [9]. Endogenous GA content was analyzed by gas chromatography-mass spectroscopy with selective ion monitoring. In particular, endogenous $\mathrm{GA}_{4}, \mathrm{GA}_{9}$, and $\mathrm{GA}_{34}$ contents were calculated from the peak area ratios of $284 / 286,298 /$ 300 , and 506/508, respectively. Data were collected three times $(n=3)$ and Duncan's multiple range test (DMRT) was conducted for comparison among treatments. The condition of each instrument for hormone analysis is provided in Additional file 2: Table S2.

\section{Protein sample preparation (EP II)}

Soybean leaf samples were washed twice with ice cold phosphate-buffered saline solution (in molecular cloning), sonicated for $10 \mathrm{~s}$ using a Sonoplus (Bandelin Electronic, Germany), and homogenized directly with a mortar-driven homogenizer (PowerGen125; Fisher Scientific, USA) in sample lysis solution composed of $7 \mathrm{M}$ urea, $2 \mathrm{M}$ thiourea containing $4 \%(w / v) 3$-([3-cholamidopropy] dimethyammonio)-1-propanesulfonate, $1 \%(\mathrm{w} / \mathrm{v})$ dithiothreitol, $2 \%(v / \mathrm{v})$ pharmalyte, and $1 \mathrm{mM}$ benzamidine. Occasionally, a bead beater was used for lysis of rigid cells. Proteins were extracted for $1 \mathrm{~h}$ at $25{ }^{\circ} \mathrm{C}$ by vortexing. After centrifugation at $15,000 \times g$ for $1 \mathrm{~h}$ at $15{ }^{\circ} \mathrm{C}$, the insoluble material was discarded, and the soluble fraction was used for two-dimensional gel electrophoresis. The protein concentration was assayed by the Bradford method [32].

\section{D PAGE (EP II)}

Immobilized $\mathrm{pH}$ gradient dry strips $(4-10 \mathrm{NL}$ immobilized $\mathrm{pH}$ gradient, $24 \mathrm{~cm}$, Genomine, Korea) were equilibrated for $12-16 \mathrm{~h}$ with $7 \mathrm{M}$ urea, $2 \mathrm{M}$ thiourea containing 2\% 3-([3-cholamidopropy] dimethyammonio)-1-propanesulfonate, $1 \%$ dithiothreitol, and $1 \%$ pharmalyte, and loaded with $200 \mu \mathrm{g}$ of sample. Isoelectric focusing was performed at $20{ }^{\circ} \mathrm{C}$ using a Multiphor II electrophoresis unit and EPS $3500 \mathrm{XL}$ power supply (Amersham Biosciences, UK) following the manufacturer's instructions. For isoelectric focusing, the voltage was linearly increased from 150 to $3500 \mathrm{~V}$ over $3 \mathrm{~h}$ for sample entry followed by a constant $3500 \mathrm{~V}$, with focusing complete after $96 \mathrm{kV} / \mathrm{h}$. Prior to the second dimension, strips were incubated for $10 \mathrm{~min}$ in equilibration 
buffer (50 mM Tris-Cl, pH 6.8 containing $6 \mathrm{M}$ urea, 2\% sodium dodecyl sulfate [SDS], and 30\% glycerol), first with $1 \%$ dithiothreitol and second with $2.5 \%$ iodoacetamide. Equilibrated strips were inserted onto SDS-PAGE gels $(20 \times 24 \mathrm{~cm}, 10-16 \%)$. SDS-PAGE was performed using the Hoefer DALT 2D system (Amersham Biosciences, UK) following the manufacturer's instruction. Two dimensional gels were run at $20{ }^{\circ} \mathrm{C}$ for $1700 \mathrm{~V} / \mathrm{h}$ and then the 2D gels were stained with colloidal Coomassie brilliant blue as described by Oakley et al. [33], although the fixing and sensitization step with glutaraldehyde was omitted.

\section{Image analysis and identification of proteins (EP II)}

Quantitative analysis of digitized images was performed using the PDQuest software program (version 7.0, Bio-Rad, USA) according to the protocols provided by the manufacturer. The quantity of each spot was normalized by total valid spot intensity. Protein spots were selected for the significant expression variation deviated over two-fold in its expression level compared to the control or normal sample.

For protein identification by peptide mass fingerprinting, protein spots were excised, digested with trypsin (Promega, Madison, WI), mixed with cyano-4-hydroxycinnamic acid in $50 \%$ acetonitrile/0.1\% TFA, and subjected to matrix assisted laser desorption/ionization-time of flight analysis (Microflex LRF 20; Bruker Daltonics, USA) [34]. Spectra were collected from 300 shots per spectrum over $\mathrm{m} / \mathrm{z}$ range 600-3000 and calibrated by two-point internal calibration using Trypsin auto-digestion peaks (m/z 842.5099, 2211.1046). The peak list was generated using Flex Analysis 3.0. The threshold used for peak-picking was as follows: 500 for minimum resolution of monoisotopic mass and 5 for $\mathrm{S} / \mathrm{N}$. The search program MASCOT, developed by Matrixscience (http://www.matrixscience.com/), was used for protein identification by peptide mass fingerprinting. The following parameters were used for the database search: trypsin as the cleaving enzyme, a maximum of one missed cleavage, iodoacetamide as a complete modification, oxidation as a partial modification, monoisotopic masses, and a mass tolerance of $\pm 0.1 \mathrm{Da}$. The peptide mass fingerprinting acceptance criterion was probability scoring.

\section{Root phenotype (EP II)}

We used the same soybean variety, but used a different soil type to measure root phenotypic difference among treatments (control and different concentrations of ETP). The sterilized soybean seeds were propagated in the six-hole pots $(455 \mathrm{~mm} \times 340 \mathrm{~mm} \times 180 \mathrm{~mm})$, which contained thoroughly washed and decomposed granite soils (overall size was 7-9 $\mathrm{mm}$ ) to reduce root sample loss. To prevent the soil from drying out, enough water was supplied in the morning (0800-0900 h) and evening (1800-1900 h). When the soybean plant reached the V2 stage, the WL treatment was applied to each soybean plant for 15 days. During the WL period, the water level was maintained daily at $10-15 \mathrm{~cm}$ above the soil surface and the root samples were collected at 5-day intervals after the WL treatment until 15 days. The decomposed granite soil was carefully removed from the pots and the root samples washed twice with distilled water. Images of the clean root samples were captured with a digital camera (COOLPIX A; Nikon, Japan) at a mini studio (W $70 \mathrm{~cm} \times \mathrm{L} 100 \mathrm{~cm}$ ). The image data was analyzed by Flower Shape Analysis System software (www.kazusa.or.jp/ phenotyping/picasos/) to measure the root surface area (RSA) [35].

\section{Antioxidant activity and mRNA expression level (EP II)}

To measure the stress response in soybean plants, we used the leaf samples. During the V2 stage, the WL treatment was applied to soybean plants for 2 days. We collected leaf samples at 1-day intervals and the same experiment was conducted three times. The fresh leaf and root samples were used to determine glutathione (GSH) and glutathione reductase (GR) activity. Briefly, $100 \mathrm{mg}$ of fresh leaf samples were homogenized in buffer containing $50 \mathrm{mM}$ Tris $\mathrm{HCl}$ (pH 7.0), $3 \mathrm{mM} \mathrm{MgCl}, 1 \mathrm{mM}$ EDTA, and 1.0\% PVP. The homogenized samples were then centrifuged at $10,000 \mathrm{rpm}$ for $15 \mathrm{~min}$ at $4{ }^{\circ} \mathrm{C}$. We used the Bradford assay for quantification of total protein content [32]. The reduced GSH was estimated by following the protocol described by Ellman [36]. The homogenate was collected by grinding leaf samples with the addition of $3 \mathrm{~mL}$ of $5 \%$ $(v / v)$ trichloroacetic acid. The supernatant $(0.1 \mathrm{~mL})$ was decanted into a tube containing $3 \mathrm{~mL}$ of $150 \mathrm{mM}$ $\mathrm{NaH}_{2} \mathrm{PO}_{4}$ (pH 7.4). Subsequently, $500 \mu \mathrm{L}$ of $5.5^{\prime}$-dithiobis (2-nitrobenzoic acid) (DTNB; $75.3 \mathrm{mg}$ of DTNB dissolved in $30 \mathrm{~mL}$ of $100 \mathrm{mM}$ of phosphate buffer, $\mathrm{pH}$ 6.8) was added to the suspension and it was incubated at $30 \pm 2{ }^{\circ} \mathrm{C}$ for $5 \mathrm{~min}$. The absorbance was measured at $412 \mathrm{~nm}$ and GSH contents were estimated by comparing with the standard curve. GR activity was measured by the protocol described by Garlberg and Mannervik [37]. A total of $150 \mu \mathrm{L}$ of enzyme was reacted with $1 \mathrm{~mL}$ of reaction mixture containing $1 \mathrm{mM}$ EDTA, $3 \mathrm{mM} \mathrm{MgCl} 2,0.5 \mathrm{mM}$ oxidized glutathione, $0.1 \mathrm{M}$ HEPES $\mathrm{pH} 7.8$, and $0.2 \mathrm{mM}$ NADPH. GR activity was measured by NADPH oxidation and monitored by decreased absorbance at $340 \mathrm{~nm}$ for $2 \mathrm{~min}$. To investigate changes in gene mRNA expression among treatments, total RNA was isolated from fresh soybean leaf tissue using TRIzol (Invitrogen, USA). Briefly, fresh soybean leaf tissue was finely ground using liquid nitrogen and $1 \mathrm{~mL}$ of TRIzol was added immediately. Samples were then centrifuged for $5 \mathrm{~min}$ at 13,000 rpm and $4{ }^{\circ} \mathrm{C}$. The supernatant was transferred to a new $1.7 \mathrm{ml}$ 
tube and chloroform and isopropanol were added for phase separation and RNA precipitation, respectively. Centrifuge steps were carried out in between. Isolated RNA pellets were washed with 75\% DEPC EtOH, dissolved in RNase-free water, and treated with DNaseI. Total RNA was used for cDNA synthesis following the manufacturer's protocol (cDNA synthesis kit, Phile, Korea). The cDNA was used as a template for real-time PCR (Eco ${ }^{\text {Tw }}$ Real-Time PCR, Illumina, USA). During the real-time PCR process, $2 \times$ Quantispeed SYBR Mix (PhileKoea) was used as the reaction mixture, and the PCR was conducted according to the manufacturer's protocol. GmUBI was used as the reference gene for data normalization and all data were replicated three times. Detailed primer information for the real-time PCR process is listed in Additional file 3: Table S3.

\section{Statistical analysis}

The experiments (EP I and EP II) were conducted three times with three replications under greenhouse and growth chamber conditions, respectively. The experiments of antioxidant activity and determination of mRNA expression level, and SNO related gene expression levels were conducted two times with three replications under a greenhouse condition. Analysis of variance (ANOVA) was tested at $P<0.05$ to evaluate significant difference among treatments, periods, replications, and treatments by periods. Comparison among treatments was conducted by the DMRT and the SAS 9.1 software program was used for statistical analysis.

\section{Results}

Plant growth characteristics with and without waterlogging (WL) stress (EP I)

To evaluate the effects of the PGRs, we monitored the plant height with and without WL stress. When we applied PGRs to soybean plant (0 DAT), the plant height was not significantly different among PGR treatments. However, the plant height was significantly $(P<0.05)$ increased by $48 \%$ ( 28 DAT, minimum value) $-56 \%$ (7 DAT, maximum value) in the $\mathrm{GA}_{4}$ treatment at $7,14,21$, and 28 days after treatment (DAT) (Fig. 1), with the plants not showing WL resistance (data not shown). A higher plant height was observed in ETP and KT applications than that seen in the WL only treatment, whereas IAA, SA, and Methyl-JA applied to soybean plants did not cause any differences or decreases in plant height compared to that in the only WL treatment (Fig. 1; 28 DAT). Soybean plants died after 14 days of WL treatment when $100 \mu \mathrm{M}$ ABA treatment was applied (Fig. 1). Results of the visual rating score (VRS) showed that WL-treated plants presented around 3.5-4.0 VRS, whereas the control plants showed 1.0 VRS at all time points. Among PGR-treated plants, IAA, KT, GA, and ETP-treated plants showed improved VRSs compared to that of WL (Fig. 1). In particular, ETP-treated plants showed the lowest VRS compared to IAA, KT, and GA applications (Fig. 1). Based on the results of Fig. 1 (plant height and VRS), we decided on IAA and ETP as provisional candidate materials; thus, we carried out additional experiments using KT and ETP. The chlorophyll content and chlorophyll fluorescence after ETP and KT applications were measured, with no significant difference shown before the WL treatment (Fig. 2). The chlorophyll content significantly decreased in all WL-treated plants. However, ETP and KT-treated plants had higher chlorophyll contents than that of the WL only treatment during the experimental periods (Fig. 2a). Moreover, the chlorophyll content was higher in the ETP application than in the KT application (Fig. 2a). Moreover, chlorophyll fluorescence of ETP and KT applied to soybean plants showed increased levels $(45-50 \%$ increase at 28 DAT) than that of the WL only treatment. In particular, chlorophyll fluorescence in ETP-treated plants was higher than that
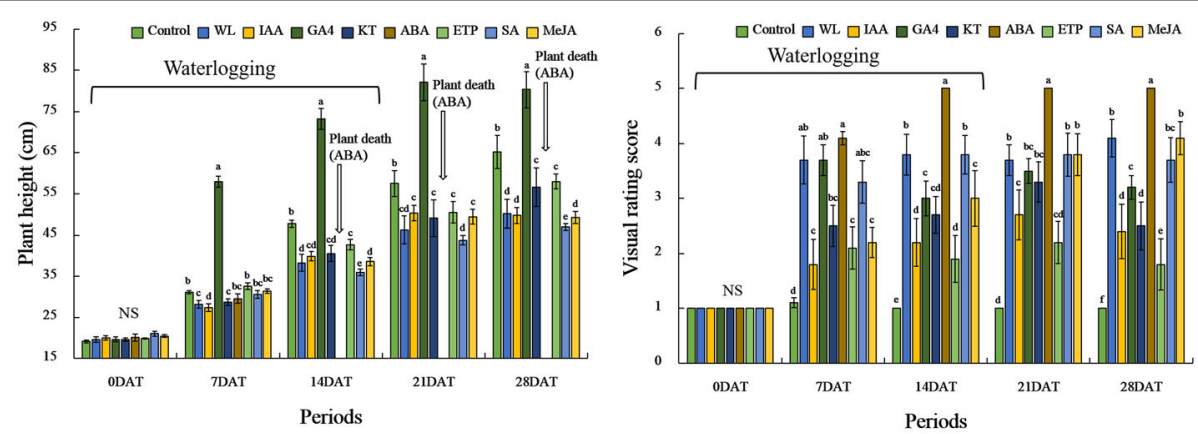

Fig. 1 Soybean plant height and visual rating score during and after waterlogging (WL) treatment. WL treatments were maintained for 14 days. In the figure, NS indicated no significant difference among treatments and plant death means no plant survival at ABA treatment. Visual rating scores: 1, no plant damage (plants healthy); 2, initial signs of wilting and curling; 3, most leaves are wilting and drooping; 4, all leaves have wilted and many are brown and crispy; and 5, death of growing point. Data were collected three times and are presented as the average \pm standard error $(n=10)$ 


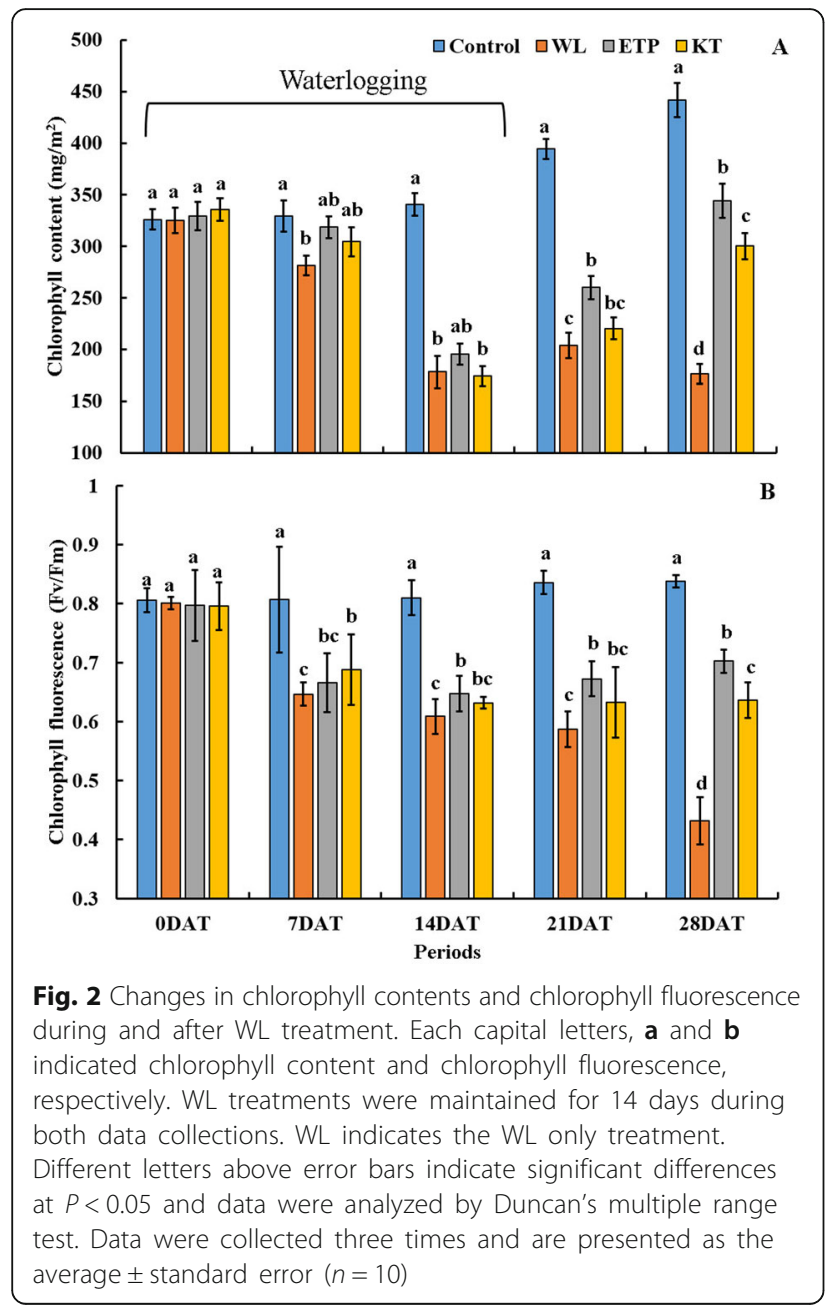

in those treated with KT (Fig. 2b). Overall, the ETP treatment showed a promising result in extending WL stress tolerance in soybeans compared to other PGRs; therefore, ETP was selected for further experiments.
Effect of ETP application on plant growth characteristics with and without WL stress (EP II)

Through the EPI, we confirmed the effects of ETP application to soybean plants under waterlogging conditions via several phenotypic variables, such as plant height, visual rating score, chlorophyll content, and chlorophyll fluorescence. These results were similar to our previous report [9]; thus, we departmentalized the concentration of ETP to identify an appropriate concentration and waterlogging tolerance mechanism. Three different concentrations of ETP $(50 \mu \mathrm{M}$ [ETP50], $100 \mu \mathrm{M}$ [ETP100], and $200 \mu \mathrm{M}$ [ETP200]) was applied to soybean plants. The plant height was lower (7.2-23.7\%) than that of the control under both stress conditions (WL only or WL with ETP treatments) (Fig. 3a). When we compared the plant height between WL only and WL with ETP applications, it was higher in ETP50 and ETP100 applications compared to that in the only WL application. On the other hand, a decreased plant height was observed in the WL with ETP200 application compared to that in the WL only treatment at 5 DAT and 10 DAT (Fig. 3a). Higher chlorophyll contents (10.3-54.7\%) were observed under non-stress conditions during all time periods (Fig. 3b). The plants that received ETP had gradually higher chlorophyll content levels depending on the concentrations of ETP than those of the WL only treatment (Fig. 3b).

\section{Effect of ETP application on chlorophyll contents and fluorescence (EP II)}

To evaluate the photosynthetic efficiency, we measured the chlorophyll fluorescence $(\mathrm{Fv} / \mathrm{Fm})$ at 15 days after WL treatment. Overall, lower OJIP curves were observed in the WL-treated and WL with ETP-treated plants than in the control (Fig. 4a). However, ETP-treated plants showed a slightly improved OIJP curve compared to that of WL-treated plants. In particular, with the phase from $J$ to $\mathrm{P}$ showing differences between ETP-treated plants and WL-treated plants (Fig. 4a). Fv/Fm showed similar results to those of the OJIP. Non-stressed soybean plants showed higher levels of $\mathrm{Fv} / \mathrm{Fm}(0.76)$ than the other treatments.
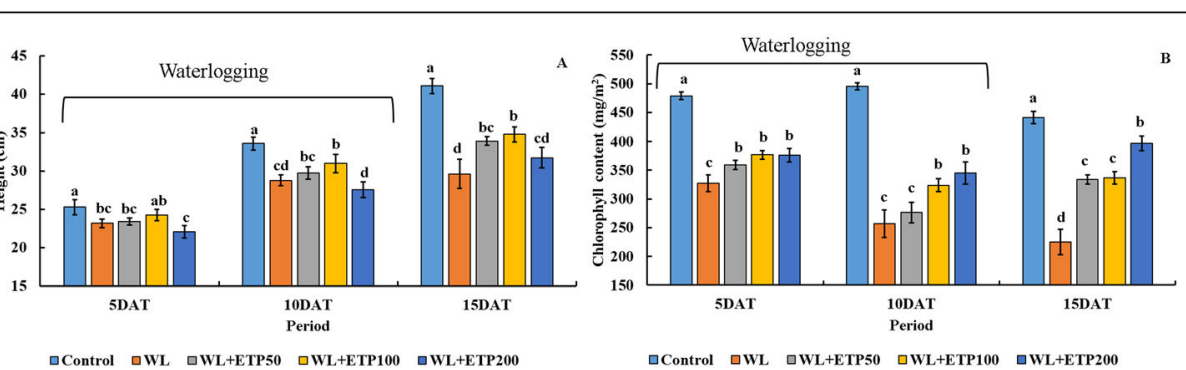

Fig. 3 Influence of various concentrations of ethephon treatment on plant height (a) and chlorophyll content (b). Soybean plants were exposed to WL for 10 days. Data were collected in 5-day intervals from three replicate samples and are shown as the average \pm standard error $(n=10)$. In the figures, different letters indicate significant difference at $P<0.05$ and data were analyzed by Duncan's multiple range test (DMRT). WL $=$ waterlogging; DAT = days after treatment; and ETP = ethephon 

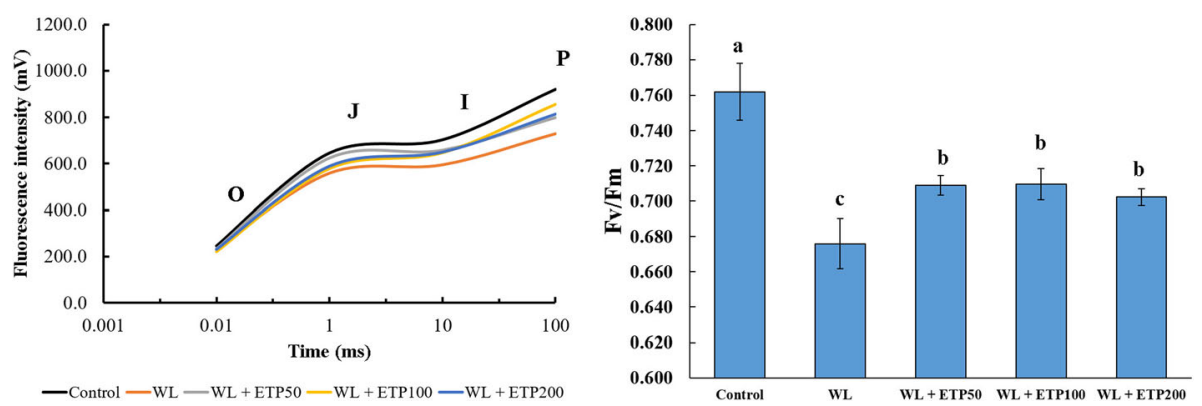

Fig. 4 OJIP parameters and photosynthetic efficiency (Fv/Fm) in soybean plants at 15 days after WL. We measured OJIP data after 20 min of dark acclimation. Data were detected by three times and are presented as the average \pm standard error $(n=10)$. WL $=$ waterlogging; DAT $=$ days after treatment; and ETP = ethephon

Comparison among WL and WL + ETP treatments showed improved Fv/Fm in ETP-treated plants (Fig. 4b).

\section{Influence of ETP application on endogenous plant hormones (EP II)}

We analyzed the levels of endogenous GA to elucidate physiological response during stress periods. In higher plants, endogenous bioactive $\mathrm{GAs}\left(\mathrm{GA}_{1}, \mathrm{GA}_{3}, \mathrm{GA}_{4}\right.$, and $\mathrm{GA}_{7}$ ) are synthesized by two different pathways, one is the early 13-hydroxylation pathway and the other is the non-13-hydroxylation pathway [38]. According to a previous study [9], soybean mainly produces bioactive $\mathrm{GA}_{4}$. via the non-13-hydroxylation pathway, and thus we focused on the determination of bioactive $\mathrm{GA}_{4}$ and its intermediate precursor $\left(\mathrm{GA}_{9}\right)$ and catabolite $\left(\mathrm{GA}_{34}\right)$. In Fig. 5, the GAs indicate the sum of $\mathrm{GA}_{4}, \mathrm{GA}_{9}$, and $\mathrm{GA}_{34}$. The GA contents showed relatively lower levels in

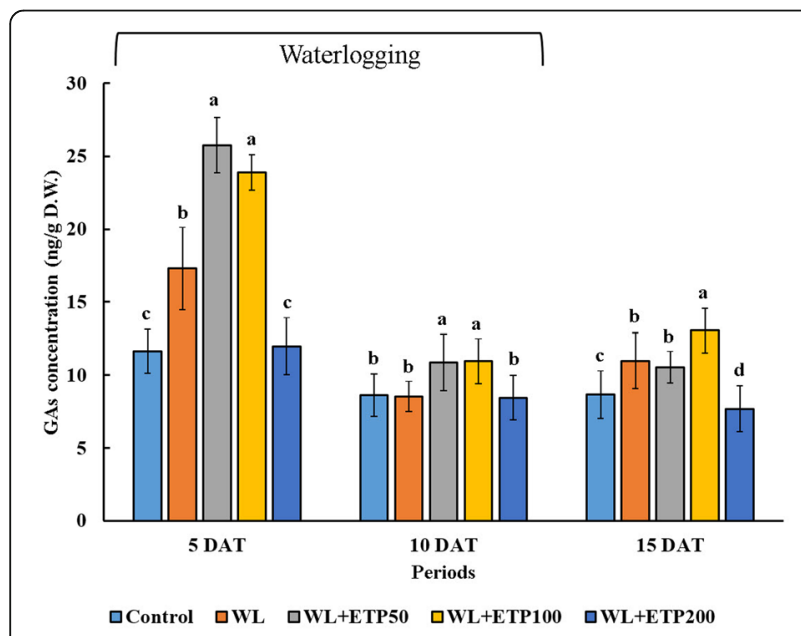

Fig. 5 Influence of different concentrations of ethephon treatments on endogenous GAs levels. Soybean plants were exposed to WL for 15 days. Data were collected at 5-day intervals from three replicate samples. Different letters indicate significant differences at $P<0.05$ and data were analyzed by Duncan's multiple range test. $\mathrm{WL}=$ waterlogging; DAT = days after treatment; ETP = ethephon; and GAs concentration = sum of $\mathrm{GA}_{4}, \mathrm{GA}_{9}$, and $\mathrm{GA}_{34}$ the control and ETP200 applications than in the other treatments (WL only, ETP50, and ETP100), whereas the GA contents were significantly higher in the ETP50 and ETP100 treatments than in the WL only treatment at 5 DAT. Enhanced levels of GA were observed in ETP50 and ETP100 at 10DAT (Fig. 5).

\section{Change in amino acid contents (EP II)}

Methionine, proline, cysteine, and glutamic acid are known as abiotic stress responses. The methionine content was significantly decreased in soybean plants grown under the WL only treatment. However, higher methionine content was measured in all ETP-treated plants than that in soybean plants grown under the WL only treatment (Fig. 6a). The same pattern was observed at all time points (5 DAT, $10 \mathrm{DAT}$, and $15 \mathrm{DAT}$ ). Proline and glutamic acid contents were significantly lower (18.4-53.6\%, $P<0.05)$ in the only WL and WL with ETP application groups than in the control, and the same tendency was observed at all time points (Fig. 6b, d). In ETP-treated plants, proline and glutamic acid contents showed statistically similar or slightly higher results than in the WL only treatment (Fig. 6b, d). Cysteine content did not show any differences among treatments in 5 DAT. When comparing the WL only and WL with ETP treatments, cysteine contents were significantly lower at 10 DAT and no differences among treatments were found at 15 DAT (Fig. 6c). The sum of the 16 amino acids (total amino acids) contents showed consistent results (Fig. 6e). Total amino acid contents were significantly lower in WL-treated plants than that of the control plants, whereas concentrations of amino acids were significantly higher in the ETP-treated plants than in the WL only treatment plants at $10 \mathrm{DAT}$ and 15 DAT (Fig. 6e).

\section{Root surface area (RSA) (EP II)}

Adventitious roots were not observed in the control soybean plants, whereas well developed adventitious roots were observed in the WL with ETP-treated plants compared to those in the WL-treated plants. The same results 

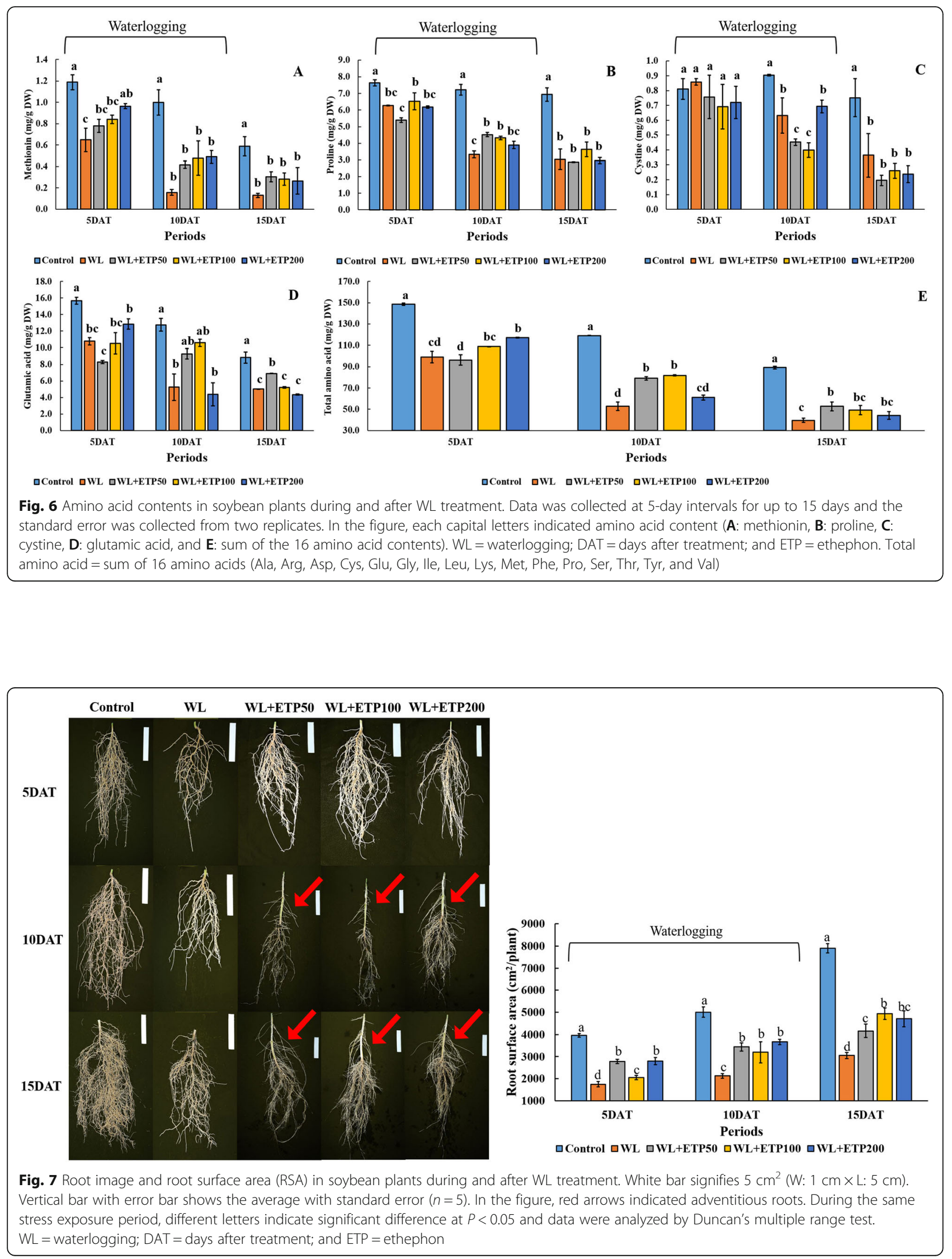


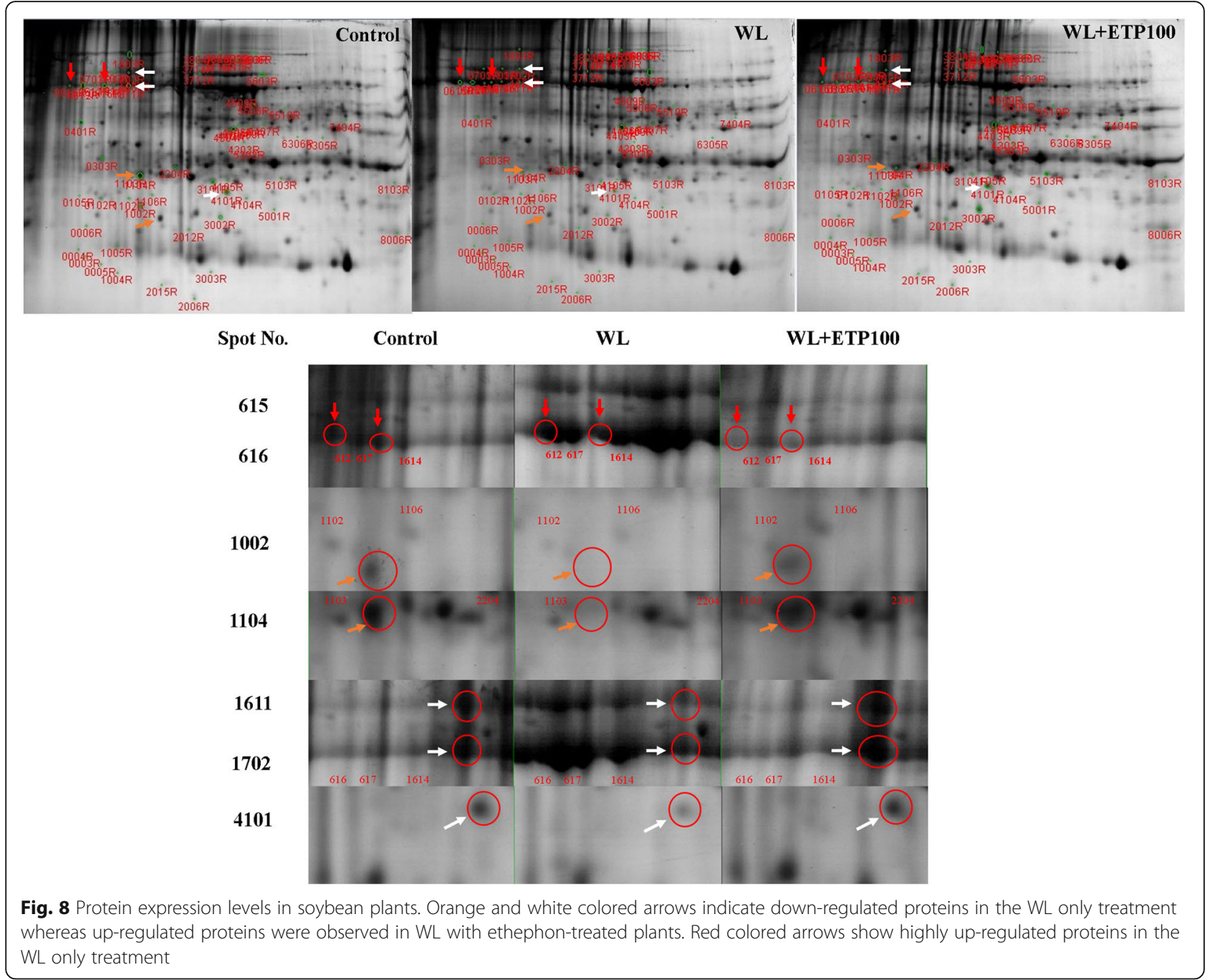

were observed at all time periods (Fig. 7). RSA analysis revealed that the control soybean plants had significantly higher RSAs than the WL- and the WL with ETP-treated plants at 5 DAT, $10 \mathrm{DAT}$, and 15 DAT. The RSA was higher in the WL with ETP-treated plants than in the WL-treated plants (Fig. 7). In particular, the application of ETP100 and ETP200 resulted in significantly higher RSAs than that did that of ETP50 at 15 DAT (Fig. 7).

\section{Proteomics expression during WL treatments (EP II)}

To identify the protein expression pattern under WL treatments, soybean plants were exposed to WL for 10 days. Two-dimensional gel electrophoresis images showed that 63 different proteins expression patterns were measured (Fig. 8). Among these 63 proteins, we selected seven interesting spots for investigation. The seven spots were identified as ribulose-1, 5-bisphosphate carboxylase/ oxygenase large subunit (Spot No. 615, 616, 1611, and 1702), trypsin inhibitor A (Spot No. 1002), glutathione S-transferase DHAR2 (Spot No. 1104), and glycoprotein
(Spot No. 4101) (Table 1). Among the seven identified proteins, two proteins (Spot No. 615 and 616; red arrows) were up-regulated in the WL only treatment compared to the control and the WL with ETP treatment, whereas five proteins (Spot No. 1002, 1104, 1611, 1702, and 4101; orange and white arrows) were down-regulated in the WL only treatment compared to the control and WL with ETP treatment (Fig. 8). Moreover, expressions of these proteins were recovered in the ETP100 treatment. Therefore, our data suggests that these proteins would be participating in inducing the resistance to WL stress.

\section{Antioxidant activity and mRNA expression level (EP II)}

According to our 2-DE results, the glutathione S-transferase DHAR2 protein was down-regulated in the WL-treated plants, but was recovered by ETP application. Thus, we measured the GSH and GR activities at the genetic and enzymatic levels. The GR activity of soybean shoots was lower in the WL- and WL with ETP-treated plants than that of the control plants (Fig. 9a). However, 
Table 1 Protein information of soybean plant exposed to waterlogging stress for 10 days

\begin{tabular}{llllll}
\hline Spot No. & MW & PI & Protein name & Score & Accession No. \\
\hline 615 & 53.03 & 6.04 & ribulose-1,5-bisphosphate carboxylase/oxygenase large subunit, partial (chloroplast) & 225 & YP_538747 \\
616 & 51.57 & 6.04 & ribulose-1,5-bisphosphate carboxylase/oxygenase large subunit, partial (chloroplast) & 212 & SBO07506 \\
1002 & 17.01 & 5.03 & trypsin inhibitor A & 119 & XP_003532237 \\
1104 & 20.77 & 5.03 & glutathione s-transferase DHAR2 & 116 & AJE59632 \\
1611 & 54.88 & 4.94 & ribulose-1,5-bisphosphate carboxylase/oxygenase large subunit, partial (chloroplast) & 204 & CAB08877 \\
170 & 66.80 & 4.94 & ribulose-1,5-bisphosphate carboxylase/oxygenase large subunit & 216 & CAB08877 \\
4101 & 18.55 & 5.91 & glycoprotein & 148 & NP_001241536
\end{tabular}

Accession number (GI number), $M W$ molecular weight, $P$ I isoeletronic point

GR activity was higher in the WL with ETP-treated than that in the WL-treated plants (Fig. 9a). The GR activity in the shoots revealed a similar pattern between 1 DAT and 2 DAT, whereas the GR activity in the roots did not show a regular pattern (Fig. 9c). Expression levels of GmGR showed differences between the shoots and roots. In the shoots, the expression levels of GmGR were lower in the WL with ETP-treated plants than in the control at 1 DAT (Fig. 10a). The expression levels of GmGR were lower in the WL with ETP-treated plants than in the WL-treated plants, whereas the expression levels of $G m G R$ were dramatically changed at 2 DAT. The most increased

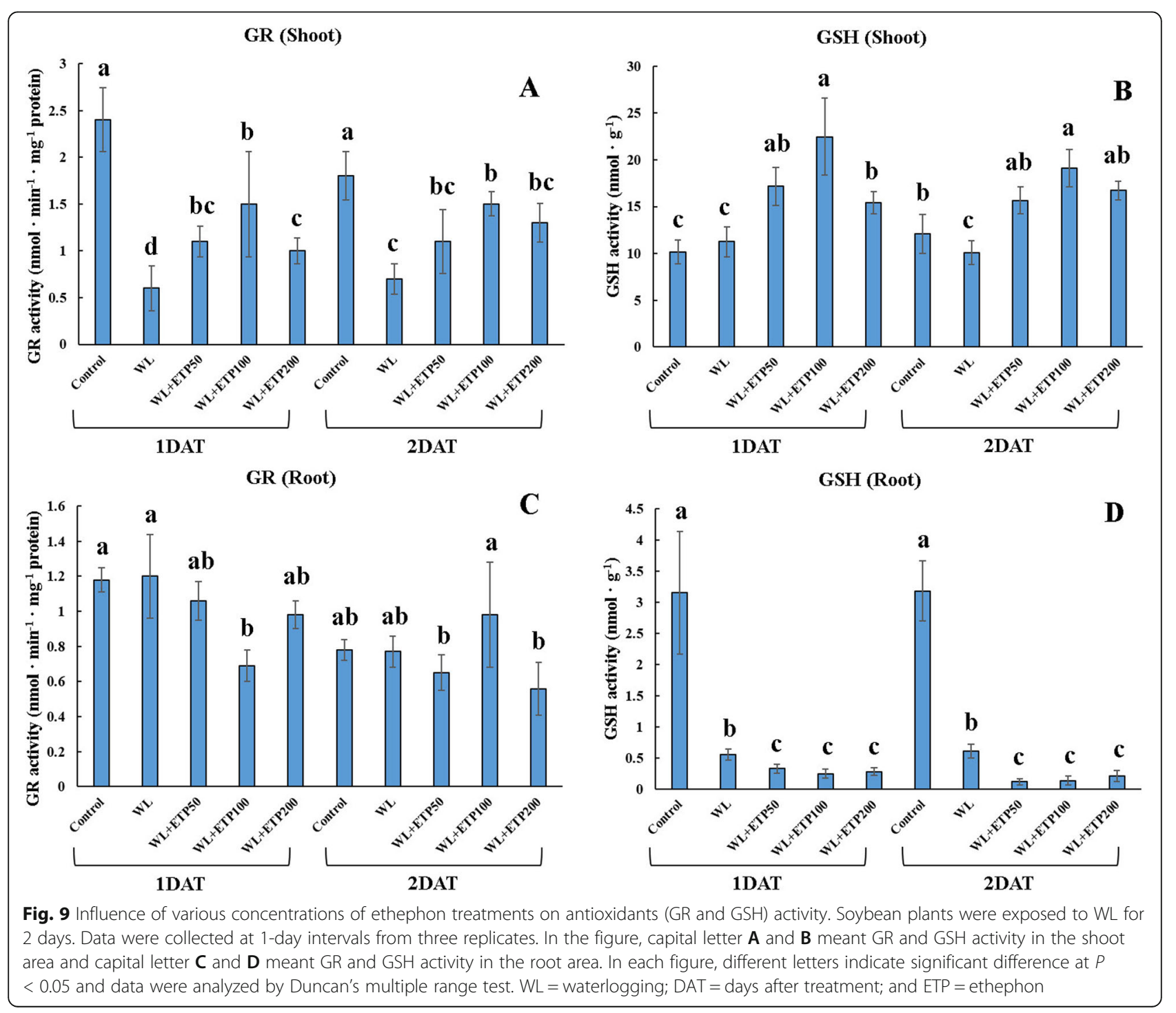




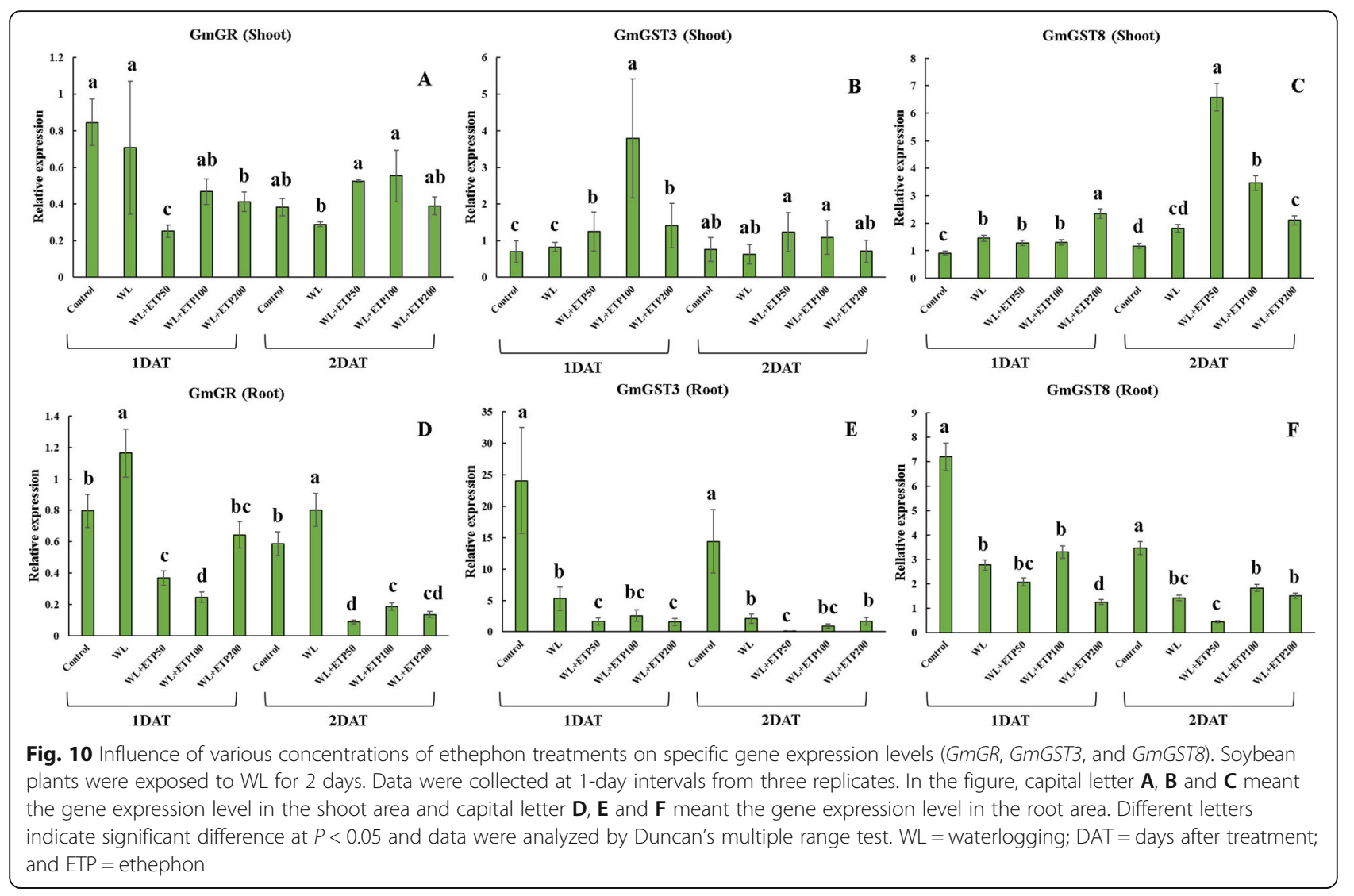

expression levels were observed in the ETP50 or ETP100 WL treatments (Fig. 10a). In the roots, the expression levels of GmGR were higher in the WL-treated plants than the other treatments, whereas the WL with ETP-treated plants showed lower expression levels than the control and WL-treated plants (Fig. 10d).

GSH activity showed significant difference $(P<0.05)$ between the shoots and roots. In the shoots, GSH activity was significantly higher in the WL with ETP-treated plants than that of the control and WL-treated plants, with a similar pattern observed during both stress exposure periods (Fig. 9b). However, GSH activity was significantly lower $(P<0.05)$ in the WL with ETP-treated plants than in the control and WL-treated plants, with the same pattern repeated during both exposure periods (Fig. 9d). At the genetic level, GSH activity was very well described in GmGST3 compared to in GmGST8 for both the shoots and roots (Fig. 10b, c, e, and f). Similarly, for GSH activity, the WL with ETP-treated plants (shoots) showed higher $(P<0.05)$ expression levels of GmGST3, while lower expression levels $(P<0.05)$ of GmGST3 were measured in WL with ETP-treated plants (roots) (Fig. 10b, e). In 1 DAT, expression levels of GmGST8 in shoots were higher in the WL only and WL with ETP treatments than in the control. However, no significant differences were found among the WL only, WL with ETP50, and WL with
ETP100 treatments (Fig. 10c). Similarly, the WL with ETP-treated plants showed different expression patterns between the shoots and roots. At 2 DAT, higher expression levels of GmGST8 were detected in WL with ETP-treated plants than were detected in the control and WL only treatment (Fig. 10c). In particular, WL with ETP50-treated plants showed the highest expression levels (Fig. 10c). In contrast, in the roots, the expression level of GmGST8 showed a similar tendency to GSH activity in soybean root. The WL with ETP-treated plants showed significantly lower expression levels than did the control (Fig. 10f). However, the expression levels of GmGST8 in the roots did not show a constant tendency among WL with ETP-treated plants (Fig. 10f).

\section{Discussion}

The mechanism behind tolerance to flooding is very well known at the genetic level in rice plants, thus several genes (Sub1A, SNORKEL1 [SK1], and SNORKEL2 [SK2]) related to flooding stress in rice plants were identified by QTL mapping [28, 42]. However, the flooding mechanism in soybean plants is not yet fully understood. Previously, Nguyen et al. [5] conducted quantitative trait locus (QTL) mapping using contrasting soybean varieties against WL to identify the flooding mechanism in soybean plants. To 
date, several QTLs involved in WL resistance $[5,39,40]$ have been reported. However, the QTLs were not narrowed down enough to identify the physiological mechanism involved or for use in marker-assisted selection [9].

In a previous study, significantly increased ET production and $\mathrm{GA}_{4}$ content, as well as decreased ABA, were observed in a WL-tolerant soybean variety. Based on previous research, we evaluated the effect of exogenous treatment with PGRs on soybean plants under WL stress in the present study. According to our results (plant height, VRS, chlorophyll content, and chlorophyll fluorescence), GA, KT, and ETP application showed a higher resistance against WL than that of the control (Figs. 1 and 2). Among the three PGR applications, we selected ETP as the candidate because, GA was not suitable to use in the agricultural industry due to large internode growth [41]. The plants that received ETP showed greater shoot growth as well as an observed decrease in leaf chlorosis than did KT-treated plants. Moreover, ETP application was theoretically closer to the results of our previous study [9]. Thus, we selected ETP as the final candidate from among several PGR treatments originally tested.

The overall plant height was higher in ETP with WL-treated plants than in the WL-treated plants. Therefore, we needed to provide evidence related to the tolerance mechanism in wetland plants to prove this difference between ETP with WL and WL only treatments. In rice plants, different resistance strategies have been identified depending on water level [28]. Hattori et al. [42] reported that increased shoot length was measured in WL-tolerant rice varieties under submergence conditions and physiological responses were induced by $S K 1$ and $S K 2$ genes. The $S K 1$ and $S K 2$ genes are included in ET response factors (ERF). Thus, this gene accumulates GA or induces GA signal transduction to increase internode elongation. Finally, different shoot lengths have been measured in deep-water rice plants [43]. We previously reported similar results [9]. According to Kim et al. [9], significantly higher bioactive $\mathrm{GA}_{4}$ was observed in WL-tolerant soybean variety than in the WL susceptible soybean variety. Therefore, based on the above evidence, we assumed that the increased shoot length from ETP application would be related to the stress avoidance strategy in soybean plants, and that endogenous bioactive GAs would participate in this response.

Photosynthesis in plants is driven mainly by two different photosynthetic apparatus: photosystem II (PSII) and photosystem (PSI) in the thylakoid membrane [44-46]. The main role of PSII is for the oxidation of water to oxygen and protons, followed by transferring protons to ATP synthase for generating ATP [45]. OJIP parameters indicate photosynthesis efficiency and have been broadly used for anticipating plant stress [47]. In the present study, when soybean plants were exposed to WL stress for 15 days, the OJIP parameter was lower in WL only and WL with ETP treatments than that of the control; however, the ETP-treated plants showed less damage than the WL-treated plants (Fig. 4). A similar pattern was measured in chlorophyll fluorescence. The $\mathrm{Fv} / \mathrm{Fm}$ values showed a decreasing tendency in the WL- and WL with ETP-treated plants; however, ETP-treated plants showed a relatively higher value than did the WL treatment (Fig. 4). If plants are exposed to salt stress, plants have decreased photosynthetic activity due to the limitation of photosynthetic electron transport [48]. In particular, oxygen evolution activity and PSII electron transport activity are significantly decreased; thus, significantly decreased fluorescence yields at J, I, and P are observed [48]. Our results show that ETP application participates in WL stress mitigation by reinforcing the photosynthetic pigment or enhancing the electron transport, because ETP-treated plants showed relatively less reduction in photosynthesis related parameters.

The plant hormone GA is known as a key signaling molecule that is involved in various physiological responses, such as seed germination, cell division, cell elongation, and stress responses $[9,38]$. In particular, GA is heavily involved in water stress escape strategies in rice plants [28]. The up-regulation of various GAs have been reported in rice plants during submergence and assist rice plants in exposing some of its parts to the atmosphere via hyper elongation of the stem [28, 42]. Finally, this physiological and morphological response offers resistance against submergence conditions in rice plants $[49,50]$. Likewise, increased bioactive $\mathrm{GA}_{4}$ contents were detected in a WL-tolerant soybean cultivar (PI408105A) [9]; therefore, these authors hypothesized that increased bioactive GA content was one of the main responses to WL stress in soybean. In the present study, significantly increased GA contents were detected in WL with ETP50- and ETP100-treated plants (Fig. 5). In particular, GA concentrations were higher in the relatively short-term (5 DAT) stress exposure. Soybean plants produce adventitious roots to survive WL stress, which is a very common response under flooding stress $[5,9,41,51]$, and these reactions were accompanied by stem swelling and root penetration, thereby leading to the development of adventitious roots [51]. Ethylene is a key regulator of adventitious root formation. Based on a study by Steffens et al. [52], penetration or growth of adventitious roots were significantly increased in the presence of $\mathrm{GA}_{3}$ and ETP-treated rice plants. Similar results were reported in other crops including petunias, tomatoes, and mung beans [53-56]. Based on previously documented evidence and our results, we hypothesized that exogenously applied ET participated in the accumulation of endogenous GA, and thus increased GA promotion not only increased plant height but also the formation of adventitious roots. 
Therefore, this physiological phenomenon is one response to escape WL stress in soybeans.

WL condition in soybean plant is a restricting factor for root growth. When soybean plants were exposed to the WL treatment for 5 days, decreased root size was observed in the WL only treatment; however, the ETP-treated plants showed greater RSA than did WL-treated plants (Fig. 7). RSA also decreased in the WL only treatment whereas ETP-treated plants showed increased RSA in all time periods. Under WL conditions, soil pores are covered with water; therefore, plants receive limited oxygen uptake and gas exchange $[13,52]$. Thus, plants produce adventitious roots to combat against stress condition. ET and GA regulate formation, number, and length of adventitious roots synergistically. Therefore, exogenous ET source application stimulates the accumulation in GA levels in soybean plants, which improve RSA. Thus, we assumed that improved RSA will participate possibility of more oxygen uptake thus plant showed resistance. As we determined via root images was decreased in the WL only treatment. However, it was improved by ETP application. Thus, our results suggested that soybean root growth was inhibited under the WL treatment. However, ETP treatment induced improved root growth therefore, ETP application to soybean plants induced resistance against WL stress conditions.

Total amino acid contents were decreased by WL; however, they were higher in ETP treatments than that in WL only treatments. In particular, methionine content revealed significant difference between WL only and WL with ETP treatments. ETP-treated plants showed higher methionine content that that of non-ETP-treated plants during WL conditions. According to a study by Koppitz [57], oxygen deficiency of underground organs due to flooding creates changes in amino acid contents and carbohydrate metabolism because oxygen participates in more than 200 different reactions, such as mitochondria respiration, oxidation, and oxygenation. Hence, high contents of amino acids have been observed in the common reed (Phragmites australis) under flooding conditions with decreased carbohydrates contents measured [57]. These results were quite different to the data obtained from the present study. According to our results, total amino acid contents and specific amino acid (methionine, proline, cysteine, and glutamic) contents decreased under both WL treatments. This distinction among amino acid contents between common reed and soybean were caused by different resistance against hypoxia or anoxia. Common reed grows in sunny, wetland habitats; fresh water marshes; and riverbanks; thus, it is well adapted to soil hypoxia [58]. Hypoxia-tolerant species can produce sufficient amounts of ATP via anaerobic fermentation whereas large amounts of carbohydrates are required to meet demands for metabolic energy [57]. Therefore, although common reed grows under flooding conditions, it produces large quantities of amino acids and huge consumption of carbohydrates. Conversely, the soybean plant is regarded as a hypoxia-sensitive species; thus, significantly decreased amino acid contents were observed. Overall amino acid contents were decreased in both WL treatments; however, ETP-treated soybean plant showed less decreases than did WL-treated plants. According to a study by Kim et al. [9], WL-tolerant soybean plants showed significantly higher endogenous ET production than did WL-susceptible soybean plants whereas significantly lower methionine contents were observed in WL-tolerant soybean plants than in WL-susceptible soybean plants. Based on previous studies, we assumed that WL-tolerant soybean plants accumulated more endogenous ET to resist WL condition. Therefore, a lower methionine content was observed in WL-tolerant plants because methionine is a precursor of ET. We induced high concentrations of endogenous ET production artificially in soybean plants resistant to WL treatment. After the ET donor source, ETP, was applied to soybean plants after WL, we found changes in amino acid contents and protein expression in soybean plants. According to our results, two proteins were down-regulated in ETP applied soybean plants compared to the control and WL-treated plants, which was identified as RuBisCO protein. The other two proteins (Spot no. 1611 and 1702) were up-regulated in ETP applied soybean plants compared to WL-treated plants, which was also known as RuBisCO protein. RuBisCO initiates carbon assimilation via carboxylation of RuBP (ribulose-1, 5-bisphophate) during $C_{3}$ photosynthesis [59]. RuBisCO is located in the chloroplasts of plants and not only participates in carbon fixation during photosynthesis but also regulates the release of used $\mathrm{CO}_{2}, \mathrm{NH}_{3}$, and energy during photorespiration [59-61]. Normally, RuBisCO is the largest protein in $C_{3}$ or $\mathrm{C}_{4}$ plant leaves; thus, approximately $30-50 \%$ of proteins are known as RuBisCO [62]. For this reason, the expression of $\mathrm{RuBisCO}$ protein showed high frequency in 2-DE analysis [59, 62]. In a study by Krishnan and Natarajan [63], a TCA/ acetone extraction procedure with a phytic acid treatment was used to deplete RuBisCO to increase the accuracy of soybean leaf protein. Therefore, we regarded that our compatible results, up- or down-regulation of RuBisCO protein in WL with ETP treatment, were not the major findings to represent the overall results. Thus, we focused more on other proteins. Three proteins, trypsin inhibitor A, glutathione S-transferase DHAR2, and glycoprotein, were up-regulated in ETP-treated plants compared to WL-treated plants (Fig. 8). Among these, in particular, we focused on the glutathione S-transferase DHAR2 because this is known as a scavenger of ROS and reactive nitrogen species via ascorbate-glutathione cycle during hydrogen peroxide [64-66]. According to a study by Foyer and Noctor [21], oxidative stress has several hallmarks, such as 
increased oxidative load, oxidative damage to cellular components, and accumulation of damaged cellular components. This can lead to loss of function in plant cells, and, ultimately, plants face death. Ascorbate and glutathione interdependently catalase in high capacity redox homeostatic $\mathrm{H}_{2} \mathrm{O}_{2}$; thus, these two enzymes are closely linked to each other $[64,67,68]$. The main function of glutathione $\mathrm{S}$-transferase is regeneration of ascorbate; therefore, DHAR is one of several routes for GSH oxidation [69]. GSH dependent enzymes, glutathione S-transferases (GSTs), are included in plants for detoxification; thus, GST-encoding genes are strongly induced by oxidative stress $[67,70,71]$. GSTs are abundant proteins and are involved in xenobiotics detoxification, as well as act as antioxidants by combining with oxidative degradation productions, acting as a glutathione peroxidase, and removing lipid peroxides $[67,71]$. For these reasons, we focused on the analysis of gene expressions involved in GSH activity (GmGR and GmGSTs) to elucidate genetic differences due to ETP supplementation after WL treatment. The expression level of GmGST3 was up-regulated in all ETP-treated plants (shoots) compared to the control and WL only treatment, and increased GSH activity was observed in ETP-treated plants (shoots). On the other hands, reduced GSH activity, as well as decreased expression levels of GmGST3, was observed in soybean plants, especially in the roots. According to Herschbach et al. [72], GSH is involved in the cell proliferation of meristematic root cells and synthesizes in the roots as well as being transported from the shoot via the phloem. Therefore, we assumed that different expression patterns of GmGST3 between the shoot and root were caused by different ROS contents. Namely, the ROS content might be increased in the shoot area under WL condition, so soybean plant need to concentrate on ROS scavengers in the shoot area, and therefore GSH transport to the root area should be reduced. ETP-treated soybean plants showed increased GSH activity and expression level of GmGST3; thus, ETP-treated soybean plants showed obvious differences between the shoots and roots. Thus, higher expression levels of GmGST3 were observed in the shoot area than in the root area. This result indicated that ETP application to soybean plants after WL could stimulate the up-regulation of GST3 expression. In other words, if soybean plants are subjected to WL conditions, ROS is rapidly accumulated in the plant cell. Therefore, the plant has to properly remove ROS to survive unfavorable environmental conditions; thus, plants operate defense mechanisms through the production of antioxidants such as CAT, APX, and GSH. In WL conditions, ethylene application induces stress mitigation in soybean plants. The application of artificial ethylene, ETP, induces the up-regulation of GST3 and GST8 in soybean plants; thus, ETP-treated soybean plants showed increased protein levels (glutathione
S-transferase DHAR2). Therefore, for soybean plants under WL conditions, genetic (GST3 and GST8) and proteomic (glutathione S-transferase DHAR2) changes due to ETP application derive various phenotypic differences such as well-developed adventitious roots, increased amino acid content, and enhanced chlorophyll fluorescence reaction.

\section{Conclusion}

Based on our results, we can summarize that under WL treatment, soybean plants experienced oxidative stress due to limited mitochondrial respiration; therefore, increased ROS decreased or suppressed morphological or physiological phenomena, such as plant height, RSA, chlorophyll content, chlorophyll fluorescence, and amino acid contents. However, ETP-treated plants showed alterations to their morphological and physiological parameters compared to WL-treated plants because ETP application induced a higher activity of antioxidants, such as GR and GSH, compared to that in the WL-treated plants. Moreover, for the antioxidant activity (GR and GSH), ETP application could stimulate a higher expression of GST3 and GST8 in the shoot area; thus, increased GST3 and GST8 consecutively induced 1) increased GSH activity (shoots), 2) decreased ROS, 3) mitigation of cell damage in photosynthetic apparatus, and 4) improved phenotype. Therefore, we hypothesize that exogenous ET application to soybean plants growing under WL stress triggers beneficial effects against WL via improved ROS scavenging, especially the up-regulation of GSH genes.

\section{Additional files}

Additional file 1: Table S1. Information on plant growth regulators (PGRs) and application concentrations. (DOCX $18 \mathrm{~kb}$ )

Additional file 2: Table S2. Gas chromatography-mass spectroscopy with selective ion monitoring and HPLC conditions for endogenous GA analysis. (DOCX $17 \mathrm{~kb}$ )

Additional file 3: Table S3. Primer sequences for qRT-PCR. (DOCX $18 \mathrm{~kb}$ )

\section{Abbreviations}

ABA: Abscisic acid; EP I: Experiment I; EP II: Experiment II; ET: Ethylene; ETP: Ethephon; GA: Gibberellins; GR: Glutathione reductase; GSH: Glutathione; GSTs: Glutathione S-transferases; IAA: Indole-acetic acid; JA: Jasmonic acid; KT: Kinetin; PGRs: Plant growth regulators; ROS: Reactive oxygen species; RSA: Root surface area; SA: Salicylic acid; SK1: SNORKEL1; SK2: SNORKEL2; WL: Waterlogging

\section{Funding}

This work was carried out with the support of the "Cooperative Research Program for Agriculture Science \& Technology Development" (Project No. PJ01367301), Rural Development Administration, Republic of Korea.

\section{Availability of data and materials}

The datasets used and analyzed during the current study are available from the corresponding author on reasonable request.

\section{Authors' contributions}

YK and CWS carried out the experiment, collected the data, and wrote the manuscript; ALK and BGM participated in 2-DE data collection as well as 
contributed to English editing and revision of the manuscript; RS, JWK, and BWY participated in hormones analysis and root data collection; SKP and IJL supervised the overall experiment and revised the manuscript. All authors read and approved the final manuscript.

\section{Ethics approval and consent to participate}

The soybean seeds, Daewon, are very a common and broadly cultivated variety in South Korea. The seeds were procured from the National Institute of Crop Science, Rural Development Administration, South Korea. Our project does not used transgenic technology, and therefore does not require ethical approval.

\section{Consent for publication}

Not applicable.

\section{Competing interests}

The authors declare that they have no competing interests.

\section{Publisher's Note}

Springer Nature remains neutral with regard to jurisdictional claims in published maps and institutional affiliations.

\section{Author details}

${ }^{1}$ Division of Plant Biosciences, Kyungpook National University, Daegu 702-701, South Korea. 'UoN Chair of Oman's Medicinal Plants \& Marine Natural Products, University of Nizwa, 616 Nizwa, Oman.

Received: 28 May 2018 Accepted: 1 October 2018

\section{Published online: 22 October 2018}

\section{References}

1. Mall RK, Lal M, Bhatia VS, Rathore LS, Singh R. Mitigating climate change impact on soybean productivity in India: a simulation study. Agric For Meteorol. 2004:12:113-25.

2. Krupa SV, Kickert RN. The greenhouse effect: impacts of ultraviolet-B (UV-B) radiation, carbon dioxide $\left(\mathrm{CO}_{2}\right)$, and ozone $\left(\mathrm{O}_{3}\right)$ on vegetation. Environ Pollut. 1989;6:263-393.

3. Munns R, Tester M. Mechanisms of salinity tolerance. Annu Rev Plant Biol. 2008;59:651-81.

4. Manavalan LP, Guttikonda SK, Tran LSP, Nguyen HT. Physiological and molecular approaches to improve drought resistance in soybean. Plant Cell Physiol. 2009:50:1260-76

5. Nguyen VT, Vuong TD, VanToai T, Lee JD, Wu X, Rouf Mian MA, Dorrance AE, Shannon JG, Nguyen HT. Mapping of quantitative trait loci associated with resistance to Phytophthora sojae and flooding tolerance in soybean. Crop Sci. 2012;52:2481-93.

6. Kim YH, Khan AL, Waqas M, Shim JK, Kim DH, Lee KY, Lee IJ. Silicon application to rice root zone influenced the phytohormonal and antioxidant responses under salinity stress. J Plant Growth Regul. 2014;33:137-49.

7. Bailey-Serres J, Fukao T, Gibbs DJ, Holdsworth MJ, Lee SC, Licausi F, Perata P, Voesenek LA, van Dongen JT. Making sense of low oxygen sensing. Trends Plant Sci. 2012:17:129-38

8. Ram PC, Singh AK, Singh BB, Singh VK, Singh HP, Setter TL, singh VP, singh RK. Environmental characterization of floodwater in eastern India: relevance to submergence tolerance of lowland rice. Exp Agric. 1999;35:141-52.

9. Kim YH, Hwang SJ, Waqas M, Khan AL, Lee JH, Lee JD, Nguyen HT, Lee IJ. Comparative analysis of endogenous hormones level in two soybean (Glycine max L.) lines differing in waterlogging tolerance. Front Plant Sci. 2015;6:714. https://doi.org/10.3389/fpls.2015.00714.

10. Valliyodan B, Ye H, Song L, Murphy M, Shannon JG, Nguyen HT. Genetic diversity and genomic strategies for improving drought and waterlogging tolerance in soybeans. J Exp Bot. 2017:68:1835-49.

11. Kreuzwieser J, Rennenberg H. Molecular and physiological responses of trees to waterlogging stress. Plant Cell Environ. 2014;37:2245-59.

12. Visser EJ, Pierik R. Inhibition of root elongation by ethylene in wetland and non-wetland plant species and the impact of longitudinal ventilation. Plant Cell Environ. 2007;30:31-8.

13. Jackson MB, Armstrong W. Formation of aerenchyma and the processes of plant ventilation in relation to soil flooding and submergence. Plant Biol. 1999;1:274-87.
14. Shimamura S, Mochizuki T, Nada Y, Fukuyama M. Formation and function of secondary aerenchyma in hypocotyl, roots and nodules of soybean (Glycine max) under flooded conditions. Plant Soil. 2003;251:351-9.

15. Shimamura S, Yoshioka T, Yamamoto R, Hiraga S, Nakamura T, Shimada S, Komatsu S. Role of abscisic acid in flood-induced secondary aerenchyma formation in soybean (Glycine max) hypocotyls. Plant Prod Sci. 2014;17:131-7.

16. Yamauchi T, Shimamura S, Nakazono M, Mochizuki T. Aerenchyma formation in crop species: a review. Field Crop Res. 2013;152:8-16.

17. Kato-Noguchi $\mathrm{H}$, Saito $\mathrm{H}$. Induction of alcohol dehydrogenase in lettuce seedlings by flooding stress. Biol Plant. 2000;43:217-20.

18. Shimamura S, Nishimura T, Koshiba T, Yamamoto R, Hiraga S, Nakamura T, Komatsu S. Effects of anti-auxins on secondary aerenchyma formation in flooded soybean hypocotyls. Plant Prod Sci. 2016;19:154-60.

19. Rosenzweig CE, Tubiello F, Goldberg R, Mills E, Bloomfield J. Increased crop damage in the U.S. from excess precipitation under climate. Glob Environ Chang. 2002;12:197-202.

20. Perata P, Armstrong W, Voesenek LA. Plants and flooding stress. New Phytol. 2011;190:269-73.

21. Koo SC, Kim HT, Kang BK, Lee YH, Oh KW, Kim HY, Baek IY, Yun HT, Choi MS Screening of flooding tolerance in soybean germplasm collection. Korean J Breed Sci. 2014:46:129-35.

22. Mustafa G, Komatsu S. Quantitative proteomics reveals the effect of protein glycosylation in soybean root under flooding stress. Front Plant Sci. 2014;5:627.

23. Oosterhuis DM, Scott HD, Hampton RE, Wullschleger SD. Physiological response of two soybean (Glycine max L. Merr) cultivars to short-term flooding. Environ Exp Bot. 1990;30:85-92.

24. Reyna N, Cornelious B, Shannon JG, Sneller CH. Evaluation of a QTL for waterlogging tolerance in southern soybean germplasm. Crop Sci. 2003;43: 2077-82.

25. Nishiuchi S, Yamauchi T, Takahashi H, Kotula L, Nakazono M. Mechanisms for coping with submergence and waterlogging in rice. Rice. 2012;5:2

26. Dat JF, Capelli N, Folzer H, Bourgeade P, Badot PM. Sensing and signalling during plant flooding. Plant Physiol Biochem. 2004;42:273-82

27. Arc E, Sechet J, Corbineau F, Rajjou L, Marion-Poll A. ABA crosstalk with ethylene and nitric oxide in seed dormancy and germination. Front Plant Sci. 2013:4:63. https://doi.org/10.3389/fpls.2013.00063.

28. Xu K, Xu X, Fukao T, Canlas P, Maghirang-Rodriguez R, Heuer S, Ismail AM, Bailey-Serres J, Ronald PC, Mackill DJ. Sub1A is an ethylene-response-factor-like gene that confers submergence tolerance to rice. Nature. 2006;442:705-8.

29. Fukao T, Bailey-Serres J. Ethylene-A key regulator of submergence responses in rice. Plant Sci. 2008;175:43-51.

30. Brodersen P, Malinovsky FG, Hématy K, Newman MA, Mundy J. The role of salicylic acid in the induction of cell death in Arabidopsis acd11. Plant Physiol. 2005;138:1037-45.

31. Yang W, Zhu C, Ma X, Li G, Gan L, Ng D, Xia K. Hydrogen peroxide is second messenger in the salicylic acid-triggered adventitious rooting process in mung bean seedlings. PLoS One. 2013;8:e84580. https://doi.org/ 10.1371/journal.pone.0084580.

32. Bradford MM. A rapid and sensitive method for the quantitation of microgram quantities of protein utilizing the principle of protein-dye binding. Anal Biochem. 1976;72:248-54.

33. Oakley BR, Kirsch DR, Morris NR. A simplified ultrasensitive silver stain for detecting proteins in polyacrylamide gels. Anal Biochem. 1980;105:361-3.

34. Fernandez J, Gharahdaghi F, Mische SM. Routine identification of proteins from sodium dodecyl sulfate-polyacrylamide gel electrophoresis (SDS-PAGE) gels or polyvinyl difluoride membranes using matrix assisted laser desorption/ionization-time of flight-mass spectrometry (MALDI-TOF-MS). Electrophoresis. 1998;19:1036-45

35. Tanabata T, Yamada T, Shimizu Y, Shinozaki Y, Kanekatsu M, Takano M Development of automatic segmentation software for efficient measurement of area on the digital images of plant organs. Hort Res. 2010;9:501-6.

36. Ellman GL. Tissue sulphydryl groups. Arch Biochem Biophys. 1959:82:70-7.

37. Garlberg I, Mannervik B. Glutathione reductase. Methods Enzymol. 1985;113: 484-90.

38. Kim YH, Choi KL, Khan AL, Waqas M, Lee IJ. Exogenous application of abscisic acid regulates endogenous gibberellins homeostasis and enhances resistance of oriental melon (Cucumis melo var. L.) against low temperature. Sci Hortic. 2016:207:41-7.

39. VanToai TT, St. Martin SK, Chase K, Boru G, Schnipke V, Schmitthenner AF, Lark KG. Identification of a OTL associated with tolerance of soybean to soil waterlogging. Crop Sci. 2001:41:1247-52. 
40. Cornelious B, Chen P, Chen Y, de Leon N, Shannon JG, Wang D. Identification of QTLs underlying waterlogging tolerance in soybean. Mol Breed. 2005;16:103-12.

41. Seo CW, Lee SM, Kang SM, Park YG, Kim AY, Park HJ, Kim YH, Lee IJ. Selection of suitable plant growth regulators for augmenting resistance to waterlogging stress in soybean plants (Glycine max L.). Korean J Crop Sci. 2017;62:325-32

42. Hattori $Y$, Nagai K, Furukawa S, Song XJ, Kawano R, Sakakibara H, Wu J, Matsumoto T, Yoshimura A, Kitano H, Matsuoka M, Mori H, Ashikari M. The ethylene response factors SNORKEL1 and SNORKEL2 allow rice to adapt to deep water. Nature. 2009;460:1026-30.

43. Hattori Y, Nagai K, Ashikari M. Rice growth adapting to deepwater. Curr Opin Plant Biol. 2011;14:100-5.

44. Aro EM, Suorsa M, Rokka A, Allahverdiyeva Y, Paakkarinen V, Saleem A, Battchikova N, Rintamäki E. Dynamics of photosystem II: a proteomic approach to thylakoid protein complexes. J Exp Bot. 2005;56:347-56.

45. Bellafiore S, Barneche F, Peltier G, Rochaix JD. State transitions and light adaptation require chloroplast thylakoid protein kinase STN7. Nature. 2005; 433:892-5.

46. Melis A. Photosystem-II damage and repair cycle in chloroplasts: what modulates the rate of photodamage in vivo? Trends Plant Sci. 1999:4:130-5.

47. Kalaji HM, Jajoo A, Oukarroum A, Brestic M, Zivcak M, Samborska IA, Cetner MD, Łukasik I, Goltsev V, Ladle RJ. Chlorophyll a fluorescence as a tool to monitor physiological status of plants under abiotic stress conditions. Acta Physiol Plant. 2016;38:102.

48. Zhang T, Gong H, Wen X, Lu C. Salt stress induces a decrease in excitation energy transfer from phycobilisomes to photosystem II but an increase to photosystem I in the cyanobacterium Spirulina platensis. J Plant Physiol. 2010;167:951-8.

49. Voesenek LACJ, Benschop JJ, Bou J, Cox MCH, Groeneveld HW, Millenaar FF, Vreeburg RA, Peeters AJ. Interactions between plant hormones regulate submergence-induced shoot elongation in the flooding-tolerant dicot Rumex palustris. Ann Bot. 2003;91:205-11.

50. Fukao T, Yeung E, Bailey-Serres J. The submergence tolerance regulator SUB1A mediates crosstalk between submergence and drought tolerance in rice. Plant Cell. 2011:23:412-27.

51. Shimamura S, Yoshida S, Mochizuki T. Cortical aerenchyma formation in hypocotyl and adventitious roots of Luffa cylindrical subjected to soil flooding. Ann Bot. 2007;100:1431-9.

52. Steffens B, Wang J, Sauter M. Interactions between ethylene, gibberellin and abscisic acid regulate emergence and growth rate of adventitious roots in deepwater rice. Planta. 2006;223:604-12

53. Phatak SC, Jaworski CA, Liptay A. Flowering and adventitious root growth of tomato cultivars as influenced by ethephon. Hortic Sci. 1981;16:181-2.

54. Robbins JA, Reid MS, Paul JL, Rost TL. The effect of ethylene on adventitious root formation in mung bean (Vigna radiate) cuttings. J Plant Growth Regul. 1985:4:147-57.

55. Pennell R, Lamb C. Programmed cell death in plants. Plant Cell. 1997;9:1157-68.

56. Clark DG, Gubrim EK, Barrett JE, Nell TA, Klee HJ. Root formation in ethylene-insensitive plants. Plant Physiol. 1999;121:53-9.

57. Koppitz $\mathrm{H}$. Effects of flooding on the amino acid and carbohydrate patterns of Phragmites australis. Limnologica. 2004;34:37-47.

58. Derr JF. Common reed (Phragmites australis) response to mowing and herbicide application. Invasive Plant Sci Manag. 2008;1:12-6.

59. Parry MA, Andralojc PJ, Scales JC, Salvucci ME, Carmo-Silva AE, Alonso H, Whitney SM. Rubisco activity and regulation as targets for crop improvement. J Exp Bot. 2013;64:717-30.

60. Sassenrath-Cole GF, Pearcy RW. The role of ribulose-1, 5-bisphosphate regeneration in the induction requirement of photosynthetic $\mathrm{CO}_{2}$ exchange under transient light conditions. Plant Physiol. 1992;99:227-34.

61. Schwender J, Goffman F, Ohlrogge JB, Shachar-Hill Y. Rubisco without the Calvin cycle improves the carbon efficiency of developing green seeds. Nature. 2004;432(7018):779

62. Mesquita RO, Soares EDA, Barros EGD, Loureiro ME. Method optimization for proteomic analysis of soybean leaf: improvements in identification of new and low-abundance proteins. Genet Mol Biol. 2012;35:353-61.

63. Krishnan HB, Oehrle NW, Natarajan SS. A rapid and simple procedure for the depletion of abundant storage proteins from legume seeds to advance proteome analysis: a case study using Glycine max. Proteomics. 2009;9:3174-88.

64. Dixon DP, Lapthorn A, Edwards R. Plant glutathione transferases. Genome Biol. 2002;3:reviews3004-1.
65. Aravind P, Prasad MNV. Modulation of cadmium-induced oxidative stress in Ceratophyllum demersum by zinc involves ascorbate-glutathione cycle and glutathione metabolism. Plant Physiol Biochem. 2005;43:107-16.

66. Yun BW, Skelly MJ, Yin M, Yu M, Mun BG, Lee SU, Hussain A, Spoel SH, Loake GJ. Nitric oxide and S-nitrosoglutathione function additively during plant immunity. New Phytol. 2016;211:516-26.

67. Edwards E, Dixon DP, Walbot V. Plant glutathione S-transferases: enzymes with multiple functions in sickness and in health. Trends Plant Sci. 2000;5:193-8.

68. Noctor G. Metabolic signaling in defence and stress: the central roles of soluble redox couples. Plant Cell Environ. 2006;29:409-25.

69. Foyer $\mathrm{CH}$, Noctor $\mathrm{G}$. Ascorbate and glutathione: the heart of the redox hub. Plant Physiol. 2011;155:2-18.

70. Queval G, Issakidis-Bourguet E, Hoeberichts FA, Vandorpe M, Gakière B, Vanacker H, Miginiac-Maslow M, Van Breusegem F, Noctor G. Conditional oxidative stress responses in the Arabidopsis photorespiratory mutant cat2 demonstrate that redox state is a key modulator of daylength-dependent gene expression, and define photoperiod as a crucial factor in the regulation of $\mathrm{H}_{2} \mathrm{O}_{2}$-induced cell death. Plant J. 2007;52:640-57.

71. Dalton DA, Boniface C, Turner Z, Lindahl A, Kim HJ, Jelinek L, Govindarajulu $M$, Finger RE, Taylor CG. Physiological roles of glutathione S-transferases in soybean root nodules. Plant Physiol. 2009;150:521-30.

72. Herschbach $\mathrm{C}$, Scheerer U, Rennenberg H. Redox states of glutathione and ascorbate in root tips of poplar (Populus tremula $\times P$. alba) depend on phloem transport from the shoot to the roots. J Exp Bot. 2010;61:1065-74.

\section{Ready to submit your research? Choose BMC and benefit from:}

- fast, convenient online submission

- thorough peer review by experienced researchers in your field

- rapid publication on acceptance

- support for research data, including large and complex data types

- gold Open Access which fosters wider collaboration and increased citations

- maximum visibility for your research: over $100 \mathrm{M}$ website views per year

At BMC, research is always in progress.

Learn more biomedcentral.com/submissions 